\title{
A participação do usuário na arquitetura e em intervenção urbana
}

\author{
User participation in architecture and urban intervention
}

Flávia Marcarine Arruda

Universidade de São Paulo (USP), Instituto de Arquitetura e Urbanismo (IAU), São Carlos, SP, Brasil

\section{Resumo}

Este artigo se concentra em discutir a especificidade e as consequências decorrentes da adoção de processos participativos na arquitetura e em intervenção urbana, os quais são entendidos aqui como as propostas que têm como ponto inicial a partilha das atividades da produção em arquitetura com o usuário. Busca-se saber se tais processos promovem, de fato, a produção de um espaço menos determinista em relação ao seu uso, a emancipação dos sujeitos e o estímulo ao sentimento de pertencimento. Com essa intenção, analisam-se, especificamente, as experiências das intervenções urbanas “O lixo não existe”, propostas pelo coletivo Basurama e realizadas em São Paulo no período de 2012-2014. Essa análise é fundamentada nas entrevistas feitas com um dos membros do coletivo e de uma participante. Para tanto, procede-se a um cruzamento entre a concepção de emancipação/dissenso de Jacques Rancière e da ética do bem-dizer da psicanálise de Jacques Lacan.

Palavras-chave: Participação. Basurama. Intervenção urbana. Emancipação. Ética da psicanálise.

\section{Abstract}

This paper seeks to understand the specificity and consequences resulting from the adoption of participatory processes in architecture and urban intervention. Participatory processes are understood, here, as proposals that have, as their starting point, sharing the activities of architectural work with the user. We asked if such processes in fact promote the production of a less deterministic space in relation to its use and the emancipation of the individual, and support a sense of belonging. With this intention we analyzed, specifically, the experiences of urban interventions "O Lixo não existe", proposed by the collective Basurama. These interventions were held in São Paulo during the period 2012-2014 and the analysis will be based on interviews with one of the collective's members and a participant. To this end, we will seek to draw a parallel between the conception of emancipation/dissent of Jacques Rancière and the psychoanalytic ethics of Jacques Lacan.

Keywords: Participation. Basurama. Urban intervention. Emancipation. Ethics of psychoanalysis.

FMA é mestranda em Teoria e História da Arquitetura e Urbanismo pelo Programa de Pós-Graduação em Arquitetura e Urbanismo da Universidade de São Paulo (IAU-USP), graduada em Arquitetura e Urbanismo pela Universidade Federal do Espírito Santo (UFES) com período sanduíche na Budapest University of Technology and Economics - Hungria (2014-2013) e intercâmbio acadêmico em Urbanismo e Meio-Ambiente na Universidade de Beijing - China (2012), e-mail: flaviamarcarine@gmail.com 


\section{Introdução}

Este artigo trata dos processos participativos na arquitetura e em intervenção urbana ${ }^{1}$, além de entender a especificidade e as consequências decorrentes da adoção de tais processos. As propostas de produção de arquitetura e intervenção urbana, tendo como ponto de partida a inclusão do usuário no processo, são denominadas aqui como participativas.

Devido à sua abrangência e seus diferentes usos, a ideia de participação - que é amplamente discutida no âmbito da História da Arte e de outros campos de estudo - corresponde aqui à partilha das atividades entre os agentes, de modo que a temática deste artigo se desenvolve em torno da análise de propostas que têm como prerrogativa a partilha de atividades entre o propositor e o usuário da proposta. 0 entendimento sobre a participação será mais bem contextualizado nas páginas seguintes, especialmente no item intitulado "O contexto do debate sobre a participação".

A análise ancora-se na questão central interessada em responder se tais processos participativos promovem, de fato, a produção de um espaço menos determinista em relação ao seu uso, a emancipação dos sujeitos envolvidos e o estímulo ao sentimento de pertencimento. Esses objetivos são os almejados pelos processos participativos, por isso a questão central se dá em torno da verificação da efetivação ou não de tais promessas.

Com essa intenção, avaliam-se, especificamente, as experiências das intervenções urbanas "O lixo não existe", propostas por Basurama, um coletivo de artistas e arquitetos espanhóis com sede em Madri, Bilbao e São Paulo, e realizadas na capital paulista no período de 2012-2014. A análise teve por base as entrevistas feitas com um dos membros do coletivo, Miguel Rodríguez, e com uma participante envolvida na intervenção no Jardim da Represa, de 2014.

As entrevistas foram mediadas por perguntas direcionadas a detalhes do projeto de intervenção, sua implementação, modos de agenciamento dos participantes e pós-intervenção. Apesar de certo grau de formulação, as questões eram abrangentes para que os entrevistados pudessem falar livremente, e algumas

\footnotetext{
${ }^{1}$ De modo geral, entende-se por intervenção urbana o espaço modificado pelo trabalho humano na escala da cidade, com caráter artístico e/ou arquitetônico, que atua fora dos circuitos oficiais como medidas de reconquista do espaço público.
}

delas foram formuladas ao longo das entrevistas, de acordo com a fala dos entrevistados.

As informações obtidas pelas entrevistas foram essenciais para compor a parte inicial deste artigo e permear todo o processo de pesquisa e cruzamento de ideias. A partir da descrição detalhada do projeto "O lixo não existe", seguiu-se para uma confluência da participação em arquitetura e nas intervenções urbanas com o embasamento teórico aqui adotado. Em seguida, discutiu-se sobre o cruzamento entre a concepção de emancipação/dissenso de Jacques Rancière e a ética do bem-dizer da psicanálise de Jacques Lacan. Por fim, fez-se a análise da participação dos usuários no projeto e apresentaram-se as considerações finais.

\section{O lixo não existe}

O coletivo Basurama, composto por arquitetos, artistas e designers, teve seu início em 2001 na Escola de Arquitetura de Madri, quando os integrantes compunham oficinas de transformação criativa de resíduos descartados em mobiliário urbano. 0 nome surgiu da junção das palavras basura (lixo em espanhol) e amor. Desde então, o coletivo passou a ser convidado por outros países para promover oficinas de intervenções urbanas em espaços públicos degradados, trabalho que ganhou notoriedade e alcançou outras 50 cidades.

Em abril de 2007, o coletivo esteve em São Paulo a convite de uma integrante do escritório paulista de arquitetura, o Darquia, com o objetivo de promover uma intervenção urbana em espaço público degradado. A partir desse convite, o coletivo foi sediado e, posteriormente, estabelecido no Brasil, tendo como representante local Miguel Rodríguez, apelidado de Mister.

Dentre os trabalhos do coletivo Basurama, faz-se a análise de "O lixo não existe", um projeto para recuperar espaços públicos deteriorados e subutilizados. Essa recuperação se dá, principalmente, pela produção de brinquedos e equipamentos urbanos que têm como matéria-prima os resíduos descartados e encontrados nas proximidades dos locais de intervenção, além de fazer uso, como procedimento, da participação dos moradores (Figura 1).

A fruição das experiências desse projeto depende de três pré-requisitos: os materiais descartados, a troca de conhecimento coletivo e a participação do usuário. 


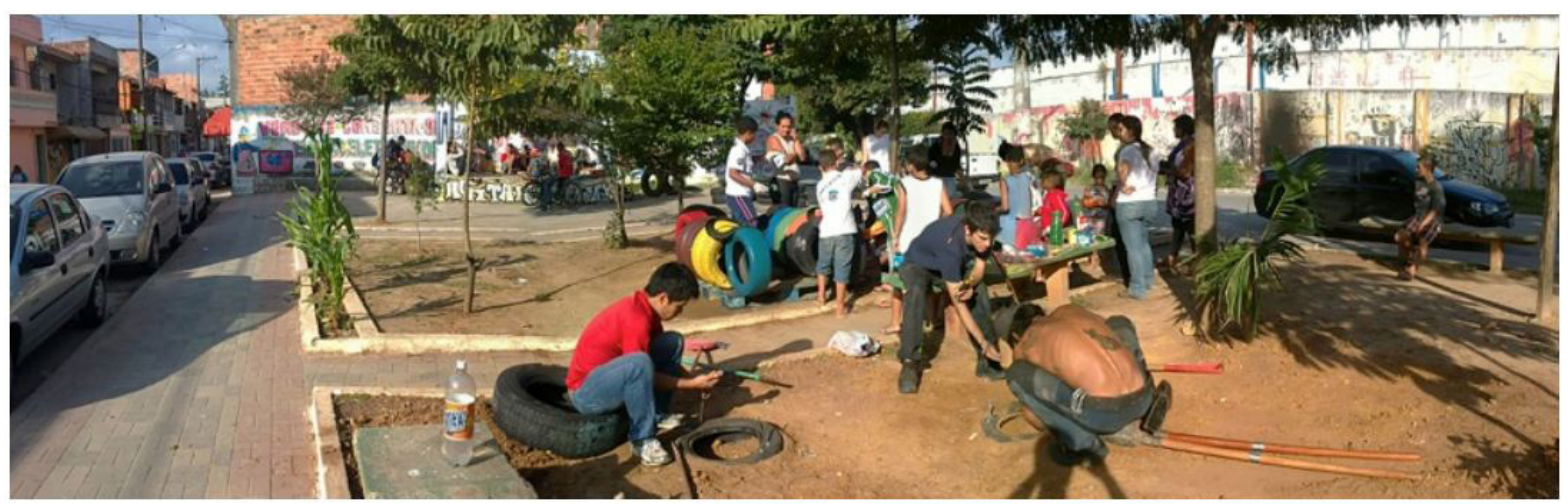

Figura 1 - Processo de montagem dos mobiliários no Jardim Keralux Fonte: Arquivo pessoal Basurama (2012).

Esse envolvimento é proposital e indispensável para que o projeto aconteça, pois a obra só existe com os participantes. Nota-se que, sem a adesão deles, não seria possível que o projeto se concretizasse, uma vez que este consiste na intervenção em espaço público para e com os participantes.

O coletivo Basurama apostou no encontro intersubjetivo sob a justificativa de que a partilha do processo com os usuários contribuiria na renovação urbana. Nessa lógica, a participação é apontada como potencial para mostrar um novo uso do espaço público aos participantes, além de mudar a relação entre ambos, que poderia passar de um estado de negligência para um status de sentimento de pertencimento.

As primeiras intervenções de "O lixo não existe" aconteceram em 2012, predominantemente na periferia da cidade de São Paulo, nos bairros Jardim Miriam, Heliópolis, Jardim Keralux, União de Vila Nova e na Escola Municipal Derville Allegretti, para atender ao Cingapura em Portal de Santana. Posteriormente, outras intervenções aconteceram em demais municípios, como em Santo André, São Bernardo do Campo e Sumaré.

A participação dos usuários tem duração de aproximadamente dois a cinco dias e pode ser compreendida em cinco partes sob uma lógica sequencial das atividades empregadas. Do primeiro ao quarto momento, ocorre a participação durante a intervenção; já o quinto momento corresponde ao pós-intervenção.

Em um primeiro momento, o Basurama identifica algum espaço público degradado e subutilizado para, em seguida, propor a participação aos moradores e instituições não governamentais locais. Como alegou Miguel Rodríguez, membro do Basurama, em entrevista ${ }^{2}$, o convite de participação é feito com tal proposta: "Troca-se lixo por parque". A identificação de tais espaços se dá por indicação de conhecidos do coletivo, como ocorreu na escolha de intervenção no Jardim Keralux - no caso, um estudante envolvido em um projeto de extensão nesse bairro. Na maioria das vezes, as associações culturais, mais que as associações de moradores, funcionam como o principal acesso do Basurama aos locais de intervenção.

Os moradores são convidados a participar e podem optar por aceitar ou não o convite. Os primeiros contatos são com instituições que ficam responsáveis por repassar o convite aos moradores, ou por meio de reuniões das associações de moradores, divulgação na rádio comunitária, ou mesmo com a publicação na agenda cultural da cidade.

Em um segundo momento, a atividade decorre da participação nas oficinas realizadas para ensinar técnicas construtivas de mobiliário urbano com materiais descartados e despertar a imaginação para as possibilidades de intervenção no espaço público (Figura 2). As oficinas ensinam a confeccionar desde equipamentos mais simples, como um banco composto por pneus, até equipamentos mais complexos, como um "elefante de pneus" e as "pneucicletas" (motocicletas de brinquedo) (Figuras 3, 4, 5, 6). A participação, nesse momento, encontra-se na ação de aprender.

Em um terceiro momento, os participantes produzem desenhos para expressar qual destino de uso do espaço público eles gostariam. No quarto momento, a partir do aprendizado adquirido nas oficinas, o coletivo

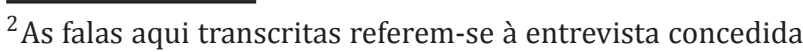
à autora.
} 


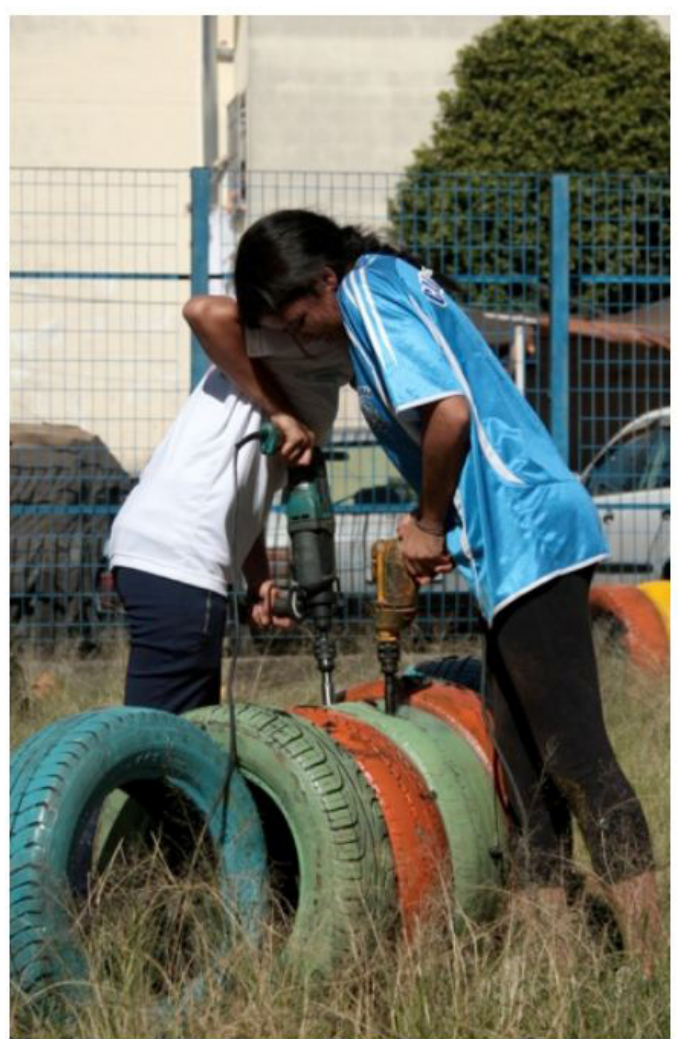

Figura 2 - Participantes no processo de construção de mobiliário em Portal de Santana

Fonte: Arquivo pessoal Basurama (2012).

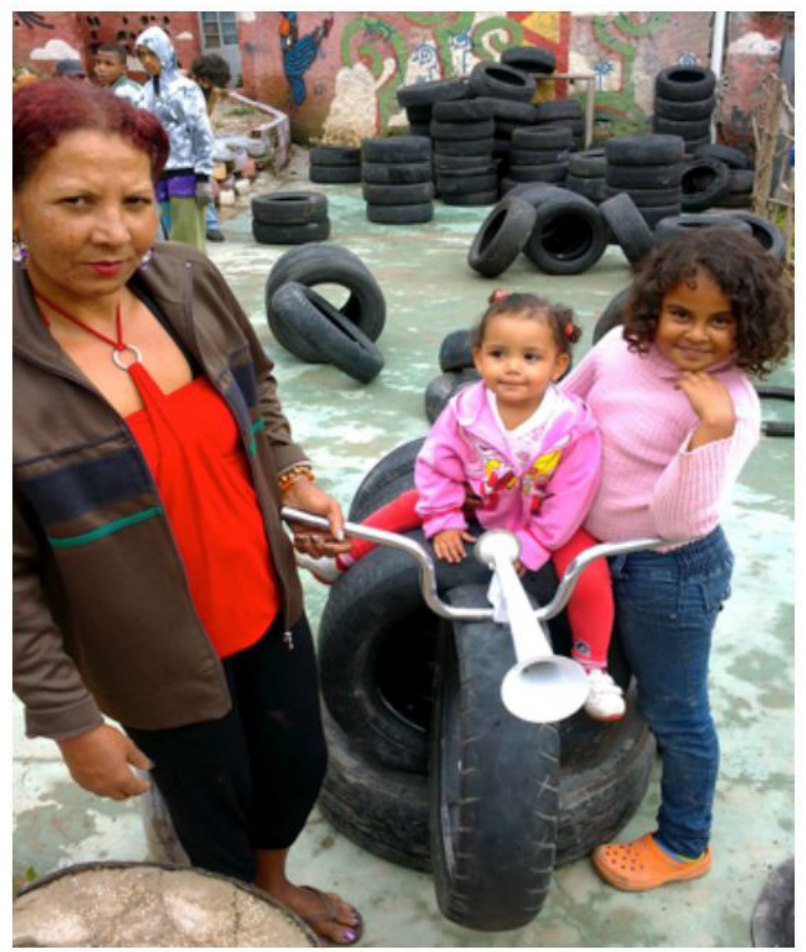

Figura 3 - "Pneucicletas" construídas no Jardim Miriam Fonte: Arquivo pessoal Basurama (2012).

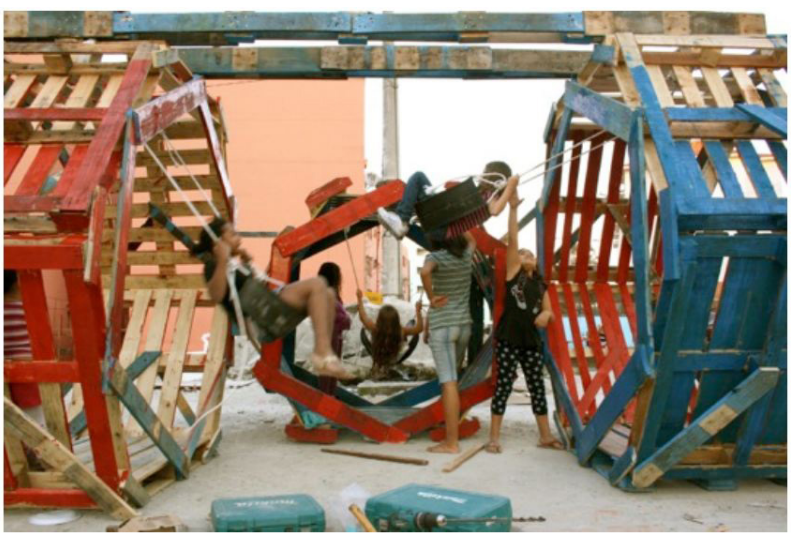

Figura 4 - Balanços construídos em Heliópolis Fonte: Arquivo pessoal Basurama (2012).

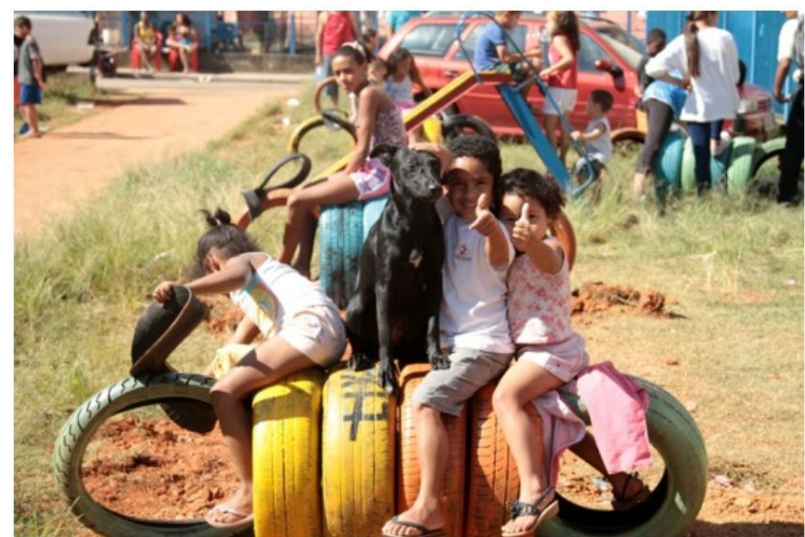

Figura 5 - Pneucicletas construídas em Portal de Santana Fonte: Arquivo pessoal Basurama (2012).

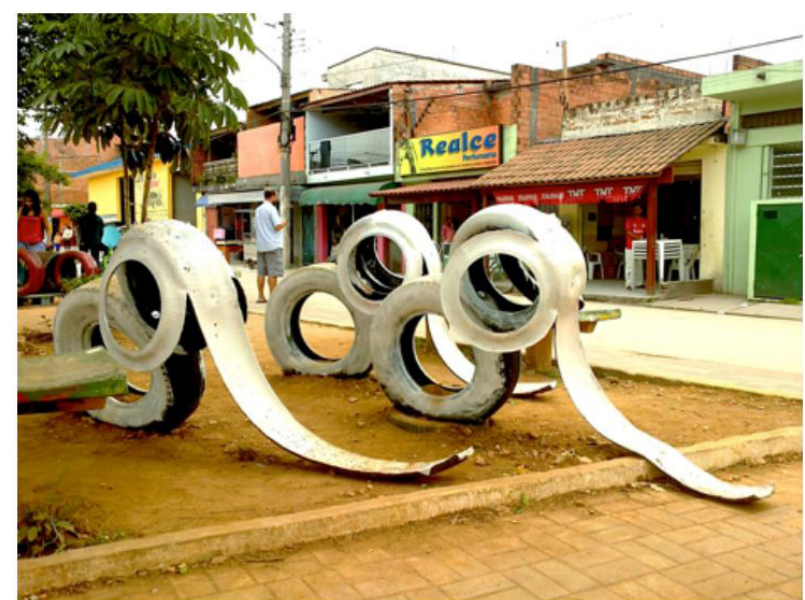

Figura 6 - Elefantes de pneu construídos no Jardim Keralux Fonte: Arquivo pessoal Basurama (2012). 
Basurama e os participantes constroem e instalam os mobiliários nos espaços públicos selecionados. A participação se encontra, então, na ação conduzida pelo saber adquirido nas oficinas.

o quinto momento se refere ao "efeito maior", esperado pelos proponentes do projeto, que seria a relação de pertencimento e uso do espaço público. Na maioria das propostas de arquitetura que partilham o processo com o usuário, há uma promessa de promover a autonomia do sujeito contra uma passividade e alienação, além da defesa do resgate da subjetividade e do estabelecimento de uma prática democrática. No caso específico da proposta aqui em análise, a participação do usuário se apoia, sobretudo, na tentativa de transformação da relação dos usuários com o espaço público, a fim de provocar um maior uso desse espaço e despertar um sentimento de pertencimento.

\section{O contexto do debate sobre a participação}

A adoção de processos participativos por parte de muitos arquitetos durante a década de 1960 evidencia-se como uma alternativa crítica ao ideário moderno, o qual se baseava no "homem-tipo" universal/padrão e na lógica funcionalista de se produzir a arquitetura e a cidade.

Além de refletir sobre os problemas de uma lógica que justifica cada parte específica de uma construção a um destino de uso $^{3}$ particular, essa crítica erigida pelos processos participativos também recaía sobre a desconsideração das singularidades dos usuários. Baseados em princípios universais, as necessidades deles eram respondidas pelos arquitetos com soluções também universais (Awan et al., 1979) que definem o uso apenas em termos funcionais e apontam para atitudes reducionistas (Lefebvre, 1991). A crítica considerava que esse funcionalismo produziria um espaço determinista em relação ao uso feito para um usuário-modelo, provocador de uma racionalização dos movimentos e de uma diminuição das sensações.

Iniciativas a partir da década de 1960 dedicaram-se ao encontro intersubjetivo entre arquiteto e usuários para que partilhassem a produção arquitetônica. Pode-se citar Lucien Kroll, arquiteto belga, como um

\footnotetext{
${ }^{3}$ A função é o uso pretendido no espaço, enquanto o uso referese ao modo como o usuário experimenta o espaço, seja por hábito ou por apropriação.
}

dos pioneiros dessas iniciativas e que influenciou a prática de Maurice Culot, Bernard Rudofsky, Nathan Silver e Giancarlo de Carlo (Awan et al., 1979). Algumas propostas de intervenções urbanas também escolheram como ponto de partida a participação do público, a exemplo dos projetos de ocupação de lotes vagos dos arquitetos Breno Silva e Louise Hanz.

Também no campo da produção artística, muitos artistas utilizaram a noção de participação do usuário para compor a obra, sobretudo a partir da década de 1960, como se nota em algumas propostas de Hélio Oiticica, a exemplo dos "Parangolés" e "Penetráveis" estruturas para serem experienciadas sensorialmente pelo sujeito-participador -, ou nas obras de Rirkrit Tiravanija, que promovia jantares para os espectadores (Bourriaud, 2009).

Diante dos diferentes campos do saber em que a participação é objeto de construção, coloca-se a seguinte questão: 0 que a crítica tem analisado sobre a adoção da participação do público em projetos de arte, arquitetura e intervenção urbana? Segundo Claire Bishop (2008, 2011), as análises sobre trabalhos participativos no campo da arte, na falta de critérios, restringem-se aos princípios éticos e, em muitos casos, desconsideram a qualidade política dessa apropriação. As análises de tais práticas, sob os princípios éticos, limitam-se a valorizar apenas aqueles projetos que visam à melhoria social e ao encontro harmonioso entre os proponentes e o público, o que resulta na exclusão da significância do comprometimento político.

A predileção por projetos de arte que valorizam um encontro harmonioso está presente no posicionamento de vários críticos com apelo ético, como na abordagem da curadora Maria Lind. Em uma publicação, ela afirma que o "Projeto Cômodo" - atividades colaborativas entre vizinhos - de um coletivo de artistas turcas seria superior ao projeto Bataille Monument de Hirschhorn. Tal afirmação é justificada por acreditar que as primeiras teriam um compromisso social ao promover encontros generosos entre vizinhos, enquanto que Hirschhorn, ao contrário, geraria encontros conflituosos por instalar sua obra em locais onde o perfil dos moradores não correspondia ao perfil do público de museus (Bishop, 2008).

A mesma situação se verifica quando se analisam as práticas participativas em arquitetura e intervenção urbana. Ao empregar critérios éticos, tais análises pressupõem que a participação do usuário, quando convergida em direção ao estabelecimento do 
consenso e ao encontro harmonioso entre proponente e público, já garantiria a produção de uma relação democrática. Essa noção está presente nas análises da participação em intervenções urbanas feitas pela arquiteta Débora Nunes (2002), na qual se pressupõe que a intercompreensão entre os atores envolvidos garante uma democracia consensual. Essa análise possui uma afinidade com o pensamento de democracia empregado por Habermas, mas se opõe à noção de democracia de Rancière, que será explicada melhor no item a seguir.

Tal posicionamento se evidencia também nos métodos de participação propostos pela arquiteta Suzanne Hofmann (2014), os quais apontam para um projeto democrático ao envolver o entendimento mútuo, a coesão na decisão e a resolução de conflitos. Giancarlo de Carlo foi outro arquiteto que enxergava a participação como um exercício democrático na arquitetura (Barone \& Dobry, 2004). Em uma publicação da Independent Magazine of Architecture+Technology (2011, p. 140) sobre um projeto Basurama, realizado em Lima, no Peru, semelhante ao "O lixo não existe", um dos pontos valorizados foi o consenso sobre o método de trabalho estabelecido entre os proponentes e os participantes. Na mesma perspectiva ética, ao analisar intervenções urbanas, Sansão (2012) concorda com Debord e com a Internacional Situacionista ao pensar a participação como um antídoto à sociedade do espetáculo, já que superaria a condição de passividade à qual a sociedade estaria submetida.

A partir de tais óticas, percebe-se que a crítica privilegiou a participação que prezava por encontros harmoniosos e que tal condição seria suficiente para garantir um estado de atividade, desalienação e democracia. A fim de superar essas análises de tendência ética sobre as práticas participativas, como tem sido feito, considera-se, neste artigo, a relevância dos aspectos políticos. Em direção contrária à ideia de democracia consensual, Jacques Rancière propõe o dissenso e a emancipação, presentes no regime político. Por intermédio do cruzamento de tais concepções com a ética do bem-dizer da psicanálise de Jacques Lacan, formam-se os critérios escolhidos aqui para a análise do projeto "O lixo não existe". Vale dizer que a ética do bem-dizer corrobora a contraposição à ética tradicional. Sendo assim, a contribuição deste artigo é refletir sobre os processos participativos por meio de aspectos políticos - não por princípios da ética tradicional - que prezam pelo encontro do proponente-público por uma via dissensual, e não consensual.

\section{O dissenso/emancipação de Rancière e a ética do bem-dizer de Jacques Lacan}

Para pensar as relações estabelecidas entre participantes e proponentes nas intervenções "O lixo não existe”, optou-se por um cruzamento teórico entre as concepções de dissenso/emancipação de Rancière e a ética do bem-dizer de Jacques Lacan, as quais tratam de relações entre especialista e público, motivo pelo qual se baseia nas obras desses autores para analisar "O lixo não existe", uma intervenção urbana que também lida com essas mesmas relações entre os proponentes especialistas e o público. Em Rancière, essa correspondência é explicitada por meio das reflexões sobre mestre-aluno e ator-espectador. Já em Lacan, essa relação é trazida entre analista-analisando.

As reflexões de Rancière e de Lacan se aproximam pelo pressuposto da existência de igualdade entre especialista-público. Ambos sugerem que, com o reconhecimento do papel intelectual de todos, não há uma distância entre eles a ser suprimida. Desse modo, a tentativa de igualar o público aos especialistas é fundadora das desigualdades.

A análise da relação especialista-público feita por Rancière (2012) inicia-se com uma reflexão sobre os espetáculos, cujas todas as formas são incluídas por ele, como a dança, o teatro, a performance e outras atividades que põem os corpos em ação diante de um público reunido, o que permite relacionar com a participação dos usuários em intervenções urbanas. Por vezes, os espetáculos, sobretudo os de teatro (assim como a arquitetura/cidade), foram considerados uma cena de ilusão e de passividade, pois os espectadores (bem como os usuários) eram aqueles que não atuavam na cena e estariam alienados ao processo de produção desse espetáculo. Nessa perspectiva, acreditava-se haver um abismo entre atores e espectadores que deveria ser solucionado.

Na tentativa de inversão dessa passividade e alienação dos espectadores, reformadores do teatro pensaram em como transformá-los em participantes ativos. Tais tentativas deram-se de dois modos: uma por meio de um espetáculo estranho ao espectador, que o forçava na busca de sentidos, e a outra pelo 
deslocamento do corpo do espectador para o espaço da ação.

Contudo, segundo Rancière (2012), essas tentativas de supressão do abismo entre atores e espectadores eram a própria fonte de criação dele, na medida em que pressupõe a existência daqueles que têm ou que não possuem capacidade. A diminuição desse abismo acontece, segundo Rancière, quando parte do pressuposto de que há uma condição ativa no espectador, pois observar também tem um status intelectual. Dessa forma, o espectador não é considerado passivo, pois, mesmo que no seu papel exista uma condição ativa, implica compreender e interpretar o que assistem.

Esse pressuposto na condição ativa do espectador é a base do princípio de emancipação trazido por Rancière, fundamentado na pedagogia emancipadora de Joseph Jacotot, pedagogo francês do início do século XIX. De acordo com tais pensadores, a emancipação intelectual do sujeito acontece no momento em que este produz uma sabedoria individual, isto é, quando assume o papel de intérprete ativo, elabora sua própria tradução e a relaciona a algo novo a ser conhecido. Rancière se apropriou da reflexão sobre a relação mestre-aluno para pensar a correspondência ator/espectador, o que auxilia em nossa análise da relação proponentes-usuário.

A pedagogia tradicional segue a lógica de causa e efeito, segundo a qual há um saber no mestre que deve ser passado para o aluno. "O que o aluno deve aprender é aquilo que o mestre o faz aprender. 0 que o espectador deve ver é aquilo que o diretor o faz ver" (Rancière, 2012, p. 18). 0 mestre, por sua vez, não é apenas aquele que sabe o que o ignorante não sabe, mas também é aquele que sabe o que, como e quando tornar objeto de saber. Segundo essa lógica, haveria uma desigualdade das inteligências, na medida em que, mesmo que o ignorante se esforçasse em saber mais sobre o que ainda ignora, isso não eliminaria a distância entre mestre-ignorante.

Em oposição, a emancipação intelectual tem como pressuposto a igualdade das inteligências. Não há uma distância entre o mestre e o ignorante, visto que há igual valor da inteligência em todas as suas manifestações. Essa lógica propõe a dissociação entre causa e efeito, o que construiria um sentido no qual o aluno aprenderia do mestre algo que este não sabe (Rancière, 2012, p. 15-18).
Na lógica emancipadora, o mestre é aquele que faz com que o aluno use da sua própria inteligência.

Ele não ensina seu saber aos alunos, mas ordena-lhes que se aventurem na floresta das coisas e dos signos, que digam o que viram e o que pensam do que viram, que o comprovem e o façam comprovar (Rancière, 2012, p. 15-16).

Nessa lógica, entre o mestre e o aprendiz emancipado, haveria um terceiro elemento, do qual nenhum deles seria proprietário. Não se trata da transmissão do saber que segue a lógica de causa e efeito, pois esse terceiro elemento manifestaria uma inteligência ignorada a priori, que passa a existir após a relação entre mestre-aprendiz. Esse efeito não pode ser antecipado, porque, para que os aprendizes/espectadores sejam ativos e ofereçam suas próprias interpretações, é necessário deixar um espaço para o inesperado acontecer.

Essa configuração em partes delineia uma ordem do sensível: aqueles que dominam (mestres) têm sua parcela e sua visibilidade no comum, enquanto que os que são dominados não possuem tal parcela, e sim uma invisibilidade. Rancière denomina essa estrutura de partilha do sensível, cuja divisão se dá entre aqueles que mandam e os que obedecem (Rancière, 2005). 0 dissenso provoca uma perturbação nessa partilha do sensível, reconfigurando-o. Assim, nessa nova configuração, os que não têm a palavra comportam-se como aqueles que a têm e, desse modo, inserem-se na ordem simbólica da comunidade dos que têm a palavra. Portanto, a partir do dissenso, há um encontro "entre" aqueles que têm e os que não têm palavra.

Opostamente ao dissenso, que não determina uma lógica de causa-efeito entre a produção e o efeito da recepção dessa produção, o consenso direciona os sujeitos para lugares, posições e sensibilidades predeterminadas, além de silenciar/ocultar os dissensos ao estabelecer os fins (a concordância entre os modos de dizer, saber e ser). Em contraposição, o dissenso tenciona o senso comum e permite reavaliar as relações com os outros e com o mundo.

O dissenso é a afirmação de uma política cuja existência ocorre "[...] quando a ordem natural da dominação é interrompida pela instituição de uma parcela dos sem-parcela [...]" (Rancière, 1996, p. 26). Essa política, sobre a qual fala Rancière, não passa pelo mesmo entendimento da política como uma organização dos poderes em um sistema por funções e consentimento da coletividade. 
A política é uma prática de igualdade, mas que não é a sua finalidade, e sim sua pressuposição como existe na educação emancipadora. A igualdade só aparece então por meio do dissenso e, por isso, é considerada uma democracia dissensual, ao contrário da democracia consensual, cujo pressuposto é o estabelecimento da parte que cabe a cada um, eliminando as possibilidades de dissenso, já que determina o regime do sensível. Na democracia consensual, as particularidades dos indivíduos e do contexto se perdem na universalidade do Estado, enquanto a democracia dissensual abre espaço para o possível, é o lugar do antagonismo, das fraturas.

Diferentemente de muitos outros autores, em que o pressuposto é na diferença, em Rancière reside na igualdade, o que embaraça as fronteiras entre os papéis de cada um, definido como um dissenso, próprio do regime político. Esse mesmo pressuposto da igualdade está presente na ética do bem-dizer de Jacques Lacan.

A ética do bem-dizer é a da psicanálise, que contesta a crença de haver um bem superior definido a priori, como age a ética tradicional e a da psicoterapia. Na condição de não haver essa crença em um bem superior, a tarefa do psicanalista não seria a de responder às demandas do analisando, pois não se acredita que esse profissional saiba o que é melhor para o outro. Dessa forma, a tarefa do psicanalista seria a de abrir espaço que permita ao analisando se apropriar do saber das manifestações inconscientes.

Lacan propõe uma política baseada na falta,

[...] onde o analista poderia comparecer com seu poder, ele tem que faltar, o que não quer dizer paradoxalmente que não seja ele que conduz o tratamento, mas que sua arma não é o poder e sim o manejo da transferência e a interpretação (Santoro, 2006, p. 62). A ética da psicanálise tem a dúvida como um papel fundamental, é de caráter investigativo ao invés de interpretativo (Kehl, 2016, p. 50).

A dimensão ética é evocada por destacar que não há garantia que a psicanálise possa provocar um tratamento psicanalítico de sucesso. Devido a essa limitação, propor um bem $a$ priori, além de não ser garantia de um resultado positivo, pode conduzir ao pior. Assim, a dimensão ética psicanalítica diz que o caminho que o analista deve seguir não é único, mas algo que se constrói em cada caso (Bispo \& Couto, 2011).
A questão ética parte da pergunta que Lacan coloca: "Agiste conforme o desejo que te habita?" (Lacan, 2008, p. 367). 0 que a psicanálise propõe para os males da atualidade é que se seja responsável pelos próprios desejos. 0 silêncio do analista faz parte da ética do bem-dizer, na qual o objetivo é permitir que o analisando se aproprie do saber inconsciente que se insinua nos sintomas e nas lacunas de sua fala, nos atos falhos e nos sonhos, isto é, nas manifestações inconscientes. Desse modo, a psicanálise tornaria o sujeito mais autônomo e menos alienado em relação às manifestações de seu inconsciente. Para a teoria lacaniana, a alienação é a condição fundadora do sujeito:

[...] parte de nós sempre nos ultrapassa, pois a linguagem 'nos fala' antes, muito antes, que falemos dela. 0 que uma análise pode fazer não é eliminar a divisão do sujeito, mas propiciar que ele deixe de responder cegamente ao desejo inconsciente (Kehl, 2016, p. 49).

A desalienação, para Lacan, não passa pela ideia de cessar as mediações entre as relações, mas conforma outro ponto de contato com o pensamento de Rancière, pois, segundo ele, todas as relações são mediadas (partilha do sensível) e cada um tem uma parte, e nunca o todo. A desalienação acontece por meio do reconhecimento do papel de todos. Trata-se de um poder comum da igualdade das inteligências, a de que todo espectador/aprendiz/analisando também pode interpretar a sua própria maneira e traçar seu próprio caminho. Todos, como espectadores, aprendem e ensinam. Tal entendimento sobre a desalienação diferencia-se, por exemplo, da concepção feita pelo arquiteto Jonathan Hill (2003). De acordo com esse autor, a participação por si já funcionaria como uma estratégia de minimização da alienação dos espectadores/usuários ao permitir que eles participem do processo de construção dos espaços.

A desalienação, em Rancière, acontece por meio de três passos: primeiro, pelo reconhecimento de não haver um pressuposto de abismo entre espectador/ator, mestre/ignorante, usuário/arquiteto; segundo, não é preciso transformar espectador em ator, nem ignorante em mestre, nem fazer o usuário ser arquiteto, para, em um terceiro passo, haver a rejeição das fronteiras que separam a posição de cada um e transpor o posicionamento mestre e aprendiz para lugares diferentes. Onde se esperaria o comandante ou o mestre, encontra-se a política fundamentada na 
falta, no "não saber" do analista/mestre emancipador, cuja prática não pretende dar preceitos ou prescrever soluções. É essa lógica de abertura que serve para que os sujeitos façam associações à sua própria maneira. A ética do bem-dizer atualiza uma contingência da igualdade, assim como o dissenso.

O dissenso/emancipação e a ética da psicanálise não pressupõem um continuum sensível como age o consenso e a ética tradicional. Ao invés de "curar" feridas, o dissenso e a ética do bem-dizer abrem feridas e possibilitam novas reavaliações sobre preconcepções de mundo. Os usuários da cidade também são os espectadores e o público de hoje, por isso, quando tais teorias pensam na relação entre especialista/público, seja ela mestre/aluno, dramaturgos/espectadores e/ou analista/analisando, pode-se transferir para a relação arquiteto/usuário.

O cruzamento teórico aqui escolhido sublinha que, segundo o pressuposto da igualdade, não há um papel privilegiado dos especialistas em relação ao público. Tal concepção faz com que propostas de participação dos espectadores na tentativa de tornálos especialistas sejam as criadoras do pressuposto da desigualdade. Em contrapartida, as propostas de participação, aliadas à lógica dissensual, promovem uma democracia dissensual e a desalienação, pois encorajam o público a despertar sua própria maneira de traçar seus próprios caminhos, sem predefini-los.

\section{Análise da participação do usuário na intervenção "O lixo não existe"}

A partir do embasamento teórico, como se pode analisar a participação do usuário e suas relações com os proponentes da intervenção "O Lixo não existe"?

Dentre os cinco momentos que envolvem a intervenção descritos anteriormente, o primeiro e o terceiro são os que lidam com propostas de intervenção "abertas", nas quais não há uma predeterminação completa da condução do participante, e sim uma potência de participação. No primeiro momento, tal abertura encontra-se no ato de os participantes escolherem se desejam participar ou não.

No primeiro momento da intervenção, que trata do convite de participação, os participantes são indispensáveis para realizá-la. Para tanto, a confiança deles é conquistada e lhes são dadas opções determinadas por um conjunto de ideias externas predefinidas. Há uma inevitabilidade da intervenção em apresentar um olhar externo e, por conseguinte, em trazer parâmetros externos para o objeto no qual interfere, pois as ditas "comunidades" possuem sua definição normalmente originada de sujeitos externos.

Ainda que esse projeto tenha se realizado em consentimento com os usuários envolvidos, a iniciativa e a decisão de reestruturar um espaço público degradado foram do Basurama, portanto externa aos usuários, e partem de uma predeterminação maior, que é a de intervir. Apesar de os espaços públicos degradados escolhidos se constituírem como uma demanda, não é possível afirmar com certeza que os participantes a considerem como demanda principal. Predeterminar uma intervenção sem consultar os usuários demonstra a permanência de uma atitude fundamentada em projetar segundo o que os proponentes pensam que os usuários querem; essa é a mesma lógica da ética tradicional, que se opõe à ética do bem-dizer lacaniana.

No terceiro momento, a intervenção demanda a produção de um desenho que expresse qual o uso que os participantes gostariam que se fosse destinado ao espaço público. 0 grau de indefinição de uma proposta abre alternativas para que os participantes definam a finalidade e, portanto, é maior do que no primeiro momento, pois se trata de possibilidades diversas ao não prever o que cada participante proporá quanto ao uso do espaço público expresso no desenho.

Ainda que os participantes trouxessem novas ideias de intervenção no espaço público, encontrariam uma limitação de execução técnica, visto que as tecnologias de mobiliários com materiais descartados, empregada pelo Basurama, não permitem que se construa todo tipo de coisa, pois são determinadas majoritariamente pelos materiais e técnicas disponíveis. Se havia alguma potencialidade da participação no terceiro momento pela possibilidade de criação, pode-se dizer que ela é desperdiçada.

Os outros momentos (segundo, quarto e quinto) tratam de ações predeterminadas pelos proponentes, nos quais já se definem, a priori, o que os participantes devem aprender nas oficinas (segundo momento), o que devem construir de mobiliário urbano (quarto momento) e como devem se relacionar com o espaço público (quinto momento). Na entrevista sobre a decisão de quais mobiliários serão construídos, Miguel Rodríguez, membro do Basurama, afirmou em entrevista: 
Eu vejo umas possibilidades por conta de alguma estrutura que já tem pronta no local e eu faço o design, e a gente chega lá com os materiais, e tem uma galera que vai participar dessa atividade.

A participante entrevistada, colaboradora do projeto no Jardim de Represa de 2014, conta passar com frequência pelo local da intervenção onde brinquedos foram instalados e nota um uso muito intenso desses mobiliários pelas crianças. De uma forma geral, os relatos em entrevistas de Miguel Rodríguez apontam que, das intervenções nas quais ele pode retornar, algumas ainda possuem os mobiliários íntegros e em uso, porém, outras não. Os mobiliários que mais sofreram alterações desde as intervenções foram aqueles instalados ao ar livre, degradados pelo uso e pelo tempo. Outros ainda foram destruídos por vizinhos, alguns com o apoio de lideranças políticas que não concordavam com as intervenções feitas de "lixo".

Nos casos em que o uso não se perpetuou no pós-intervenção, os mobiliários construídos encontravam-se degradados e sem condições de uso. Provavelmente, o grau de deterioração se deve em função das técnicas precárias de construção, mas também se nota uma ausência de engajamento dos usuários para reparar os danos causados pelo uso dos mobiliários ou mesmo uma atitude de depredação pelos próprios moradores que continuaram a não concordar com a intervenção. 0 projeto do Basurama quis mostrar um novo entendimento do uso do espaço público para os usuários, mas, em alguns casos, não teria sido suficiente para que continuassem como responsáveis por ele do modo como a proposta esperava.

Nota-se que houve modos diferentes na repercussão das intervenções nos lugares onde aconteceram. Alguns casos apontaram para um uso e cuidado com o espaço. Opostamente, em outros casos, a relação se manifestou pelo dano causado aos mobiliários construídos, seja por uso excessivo ou por não aceitação da proposta.

Hertzberger (1999) aponta que a participação dos usuários nos processos de produção do espaço gera um sentimento de pertencimento, na medida em que fortalece os vínculos ${ }^{4}$ de quem participa. Bonnemaison \& Cambrézy (1996) também se aproximam da perspectiva de Hertzberger, ao reforçar que o

\footnotetext{
${ }^{4}$ Os vínculos dizem respeito ao número de ações e relações sociais empregadas em um espaço.
}

sentimento de pertencimento fortifica os laços com o território, seja por meio de valores materiais, éticos, simbólicos ou afetivos. Independentemente se o uso dos espaços foi ou não como o Basurama pretendia, os moradores atribuíram e continuam a atribuir novos sentidos para os espaços de intervenção, mesmo que seja por um viés destrutivo. Assim, se antes os espaços públicos de intervenção estavam em desuso, após as intervenções passaram a ser ressignificados de diferentes modos.

Na concepção de "O lixo não existe", havia um pressuposto de um continuum sensível entre o modo como o Basurama esperava que os participantes tivessem e o comportamento que eles poderiam ter de fato. A intervenção preocupou-se em revelar uma forma de convívio coletivo, mas o colocou como prioridade, sem considerar as especificidades dos indivíduos que o compuseram. Ao pressupor esse continuum sensível, o projeto encara os participantes como uma comunidade, uma união coletiva consensual. Essa mesma lógica, de quando o propositor espera que a sua proposta seja compreendida pelo participante de mesmo modo que o previsto na concepção, é entendida por Rancière (2012) como similar à "pedagogia tradicional" e oposta à emancipação intelectual/dissenso.

Tais ações são conduzidas a partir do saber transmitido, no qual se espera que a compreensão dos participantes decorra daquilo que lhes foi proposto, o que pressupõe a lógica de causa e efeito da pedagogia tradicional. Na lógica do espectador emancipado, não há ponto de partida privilegiado, e sim pontos de partida. Nesse caso, cabe questionar se houve troca de papel e poderes entre participantes e proponentes. Durante a intervenção do Basurama, nota-se o estabelecimento de papéis definidos, entre os que instruem e os que são instruídos; os proponentes agem como titulares de certo poder devido à sua posição de profissionais especializados. Pode-se questionar se tal prática não levaria a uma restrição da potência de uso do espaço ou de uma condução inesperada da intervenção pelo poder decisório dos participantes. Tais intervenções tornam os participantes conscientes de seu poder intelectual?

Há um caminho para o saber dos participantes, mas que não é o da emancipação/dissenso. A proposta "O lixo não existe" é definida e formulada de uma maneira externa aos participantes envolvidos e permanece praticamente inalterada durante todo o processo, desde a sua concepção até sua realização, nos locais de intervenção. Apesar de haver um intercâmbio 
de técnicas construtivas entre os proponentes e os participantes, percebe-se que o grau de "contaminação" é muito maior em relação aos participantes do que os proponentes. A possibilidade de reorganização do sensível e abertura de dissensos se perde no caráter universal da proposta.

De acordo com Foucault \& Deleuze (1979), quando os intelectuais falam em nome dos oprimidos por julgarem que estes não teriam a consciência de suas condições, reforçam uma atitude fundamentada no seu status privilegiado. Quando uma ideia de reforma/reinvindicação é exterior à parte interessada, quando é proclamada de uma forma representativa, segundo Foucault \& Deleuze (1979, p. 4), não seria nada mais do que a remodelagem do poder.

Em sua totalidade, a intervenção demonstra a crença em uma desigualdade intelectual e atribui ao ensino a tarefa de reduzir essa distância entre os que instruem e os que são instruídos. Assim, a desigualdade é o ponto de partida, e a igualdade, o objetivo. Para Jacotot e Rancière (apud Rancière, 2002, p. 89), essa conduta é a eternização da desigualdade, visto que reproduz a própria existência, na qual o que embrutece não é a falta de instrução, mas a crença na inferioridade de sua inteligência. Afinal, é o coletivo que tem a necessidade de intervir/instruir ou são os participantes que necessitam ser ajudados?

Os participantes são instruídos à maneira dos proponentes. A prática do mestre ignorante e do psicanalista de uma ética do bem-dizer não pretende dar preceitos ou prescrever soluções. É essa lógica de abertura que serve para que o analisando e o sujeito emancipado façam associações à sua própria maneira, então é exatamente aí que se estabelece a possibilidade de emancipação e de dissenso. Se na proposta do coletivo existe dissenso, este não está no efeito esperado pelos proponentes do projeto, por não ser antecipado. 0 dissenso só aconteceria no momento em que os participantes fossem estimulados a assumir o papel de intérpretes ativos por meio da elaboração de suas próprias traduções, ao relacionarem o projeto a algo novo a ser conhecido, e quando ensinassem algo que eles mesmos ignoram.

\footnotetext{
${ }^{5}$ Estudos antropológicos apontam que o próprio ato de observar já influencia o cotidiano de uma comunidade: "[...] pois quando o pesquisador se revela para qualquer sujeito como um novo elemento do seu cotidiano, preocupado em investigá-lo, é inevitável a ocorrência de algum tipo de alteração." (Fantinel \& Silva, 2014, p. 3).
}

0 projeto do Basurama não ressalta características do campo, e sim modifica aquilo que já havia, para, então, inserir um modelo externo ao meio. Além disso, nota-se que os participantes não decidem o local de intervenção, as técnicas construtivas e a proposta. Questiona-se se os proponentes não se colocam muito mais como sujeitos potencialmente conhecedores e proprietários de um saber maior, como na ética tradicional, ao invés de adotarem uma prática guiada pela ética do bem-dizer ou pela lógica do mestre ignorante, concepções que promovem uma igualdade entre sujeitos.

A influência do Basurama sobre quem participa pode ser "boa" ou "ruim". Porém, não cabe a este artigo ressaltar se a "verdade" proposta pela intervenção é positiva ou negativa diante da "verdade" dos participantes envolvidos. Segundo Kapp (2005), não existem funções que possam ser tomadas como naturais e diretamente relacionadas ao corpo, já que são de caráter social e, portanto, criadas e cultivadas. Mesmo que se fale de uma necessidade natural e universal, quando se analisa essa problemática historicamente e geograficamente, nota-se que se confirma uma organização social. Natureza e cultura estão interligadas de forma que, quando se trata da satisfação de uma necessidade da construção como abrigo, não é possível entendê-las separadamente.

A fabricação de necessidades está atrelada às mesmas ideias que regem o mercado de consumo, no qual o que a "indústria arquitetônica" produz é em função do valor de troca, e não pelo valor de uso. Segundo Theodor Adorno (1942, apud Ferro, 1980), as necessidades são construídas socialmente; assim, não se poderia afirmar que mesmo a necessidade de abrigo é natural e inerente aos seres humanos.

No Movimento Moderno, os principais representantes apontaram para as especificações de funções para a habitação, para a cidade e para as atividades de lazer, direcionadas a um homem-modelo. 0 pensamento que tem por algum engajamento social também se orienta por necessidades padronizadas, por um homem-modelo e pela tentativa de uma sociedade livre de conflitos (Kapp, 2005). Tal postura é identificada na proposta do Basurama, visto que os integrantes apostam na noção de um continuum sensível entre a proposta e a percepção que os participantes deveriam ter em busca de uma sociedade estável.

A funcionalidade também é uma forma de controle. As funções determinadas pela proposta "O lixo não 
existe" são definidas a priori, isto é, antes do uso, da experiência. Tais funções impõem aos participantes o que se pensa saber aquilo que é o "melhor" para o outro, como na lógica da ética tradicional. Definições a priori contrariam a ideia de que há um potencial de autonomia de decisão dos usuários. As necessidades criadas pela sociedade não são absolutas, podem ser reinventadas, mas, se há uma predeterminação das decisões do usuário, isso diminuiria as possibilidades de promover a autonomia deles. E, como respondeu Rancière (2010, p. 127) em uma entrevista:

Todas as obras que se propõem como interativas, de certa maneira, definem as regras do jogo. Então, esse tipo de obra pode acabar sendo mais impositivo do que uma arte que está diante do espectador e com a qual ele pode fazer o que bem entender.

\section{Considerações finais}

Como mencionado na Introdução, o artigo baseou-se em entrevistas feitas a Miguel Rodríguez, membro do Basurama, e a uma participante envolvida na intervenção no Jardim da Represa em 2014. Por se tratar de pontos de vista de apenas dois entrevistados, tal artigo não pretende se exaurir em conclusões absolutas nem anseia oferecer um modo de pensamento único para outros casos, mas abrir discussões a respeito da participação. Cada intervenção urbana precisa ser estudada dentro de seu próprio contexto, em consideração às suas especificidades. 0 tema da participação é bastante complexo, especialmente por envolver uma diversidade de atores. Uma análise de um objeto construído no âmbito social e cultural não pode ser absoluta, pois está em constante reformulação teórica. Apoia-se em questões sobre a participação consideradas pertinentes para a discussão proposta, com atenção às próprias limitações do espaço textual de um artigo, o qual não comportaria a realização de mais entrevistas e entrevistados.

As experiências do projeto "O lixo não existe", analisadas aqui, ensaiaram uma alternativa em relação ao modo de operação segregacionista e excludente do domínio público. 0 processo funcionou como um antídoto ao estado de indiferença e individualismo nos espaços públicos contemporâneos, além de revisar o lugar do lixo. A intervenção trouxe novas possibilidades de integração entre os moradores, funcionou como catalisadora de proximidade e conexões entre os indivíduos e com o próprio espaço.

Porém, apesar de trazer benefícios para os participantes, não se pode ocultar conflitos decorrentes dessa prática. Pondera-se em que medida a proposta mais afeta quem participa do que é afetada pela vontade de quem a propõe. Colocou-se em questão se os proponentes da intervenção não se dispuseram muito mais como sujeitos potencialmente conhecedores e proprietários de um saber maior, como é observado na ética tradicional, ao invés de adotarem uma prática guiada pela ética do bem-dizer ou pela lógica dissensual.

Houve uma inevitabilidade da intervenção em apresentar um olhar externo e, por conseguinte, em trazer parâmetros externos para o objeto no qual interfere, pois as ditas "comunidades" possuem sua definição normalmente originada de sujeitos externos e pertencentes à classe intelectualmente hegemônica. Predeterminar uma intervenção sem consultar os usuários demonstra a permanência de uma atitude fundamentada em projetar segundo o que os proponentes pensam que os usuários querem. Apesar de dispor de um conhecimento específico, o arquiteto não é um conhecedor de todas as coisas, não domina um saber maior sobre o que pode ser o "melhor" para os usuários, por isso a reflexão crítica ocupa a posição de analisar sobre uma ótica menos contraditória.

Pode-se concluir que o projeto "O lixo não existe" não lida com a possibilidade dissensual de despertar antagonismos e evidenciar fraturas para uma reconfiguração do sensível e novas percepções do mundo. A proposta se aproximou de um fazer consensual como atua a ética tradicional com base no continuum sensível. Reafirma-se a importância de que uma proposta de intervenção não traga tantos pressupostos sobre comportamento e papéis sociais, mas que formule os projetos dentro de uma ótica dissensual, para que quem participa possa ressignificar a proposta.

\section{Referências}

Awan, N., Schneider, T., \& Till, J. (1979). Participation. Sheffield: University of Sheffield. Recuperado em: 13 de abril de 2015, de http:// www.spatialagency.net/database/ how/empowerment/participation.1970s 
Barone, A. C. C., \& Dobry, S. A. (2004). Arquitetura participativa na visão de Giancarlo de Carlo. Pós - Revista do Programa de Pós-Graduação em Arquitetura e Urbanismo da FAU-USP, 15(15), 18-31. http://dx.doi.org/10.11606/ issn.2317-2762.v0i15p18-31.

Bishop, C. (2008). A virada do social e seus desgostos. Concinnitas, 1(12), 145-165.

Bishop, C. (2011). Antagonismo e estética relacional. Revista Tatuí, 12, 109-132.

Bispo, F. S., \& Couto, L. F. S. (2011). Ética da psicanálise e modalidades de gozo: considerações sobre o Seminário 7 e o Seminário 20 de Jacques Lacan. Revista Estudos de Psicologia, 16(2), 121-129.

Bonnemaison, J., \& Cambrézy, L. (1996). Le lien territorial: entre frontières et identités. Géographies et Cultures, 20, 7-18.

Bourriaud, N. (2009). Estética relacional. São Paulo: Martins Fontes.

Fantinel, L. D., \& Silva, A. R. L. (2014). Dilemas e implicações do uso da observação enquanto técnica em detrimento da etnografia. In Anais do XXXVIII Encontro ANPAD (p. 13-17). Rio de Janeiro: ANPAD.

Ferro, S. O canteiro e o desenho. São Paulo: Projeto Editores Associados, 1980.

Foucault, M., \& Deleuze, G. (1979). Os intelectuais e o poder. Microfísica do poder (p. 69-78). Rio de Janeiro: Graal.

Hertzberger, H. (1999). Lições de arquitetura (2a ed). São Paulo: Martins Fontes.

Hill, J. (2003). Actions of architecture: architects and creative users. Londres: Routledge.

Hofmann, S. (2014). Architecture is participation. Berlim: Jovis.

Independent Magazine of Architecture+Technology. (2011). Basurama. Strategy and Tatics in Public Space. 38, 136-141.
Kapp, S. (2005). Por que Teoria Crítica da Arquitetura? Uma explicação e uma aporia. In: M. L. Malard (Org.). Cinco textos sobre arquitetura (p. 115-167). Belo Horizonte: Editora UFMG.

Kehl, M. R. (2016). Ética e técnica. Revista Viver Mente e Cérebro "Memória da Psicanálise”, 4, 46-55.

Lacan, J. (2008). Seminário, livro 7: a ética da psicanálise, 1959-1960. Rio de Janeiro: Jorge Zahar Ed.

Lefebvre, H. (1991). A vida cotidiana no mundo moderno. São Paulo: Ática.

Nunes. D. (2002). Pedagogia da participação: trabalhando como comunidades. Salvador: Unesco/quarteto.

Rancière, J. (1996). O desentendimento: Política e Filosofia. São Paulo: Ed. 34.

Rancière, J. (2002). O mestre ignorante: cinco lições sobre a emancipação intelectual. Belo Horizonte: Auténtica.

Rancière, J. (2005). A partilha do sensível: estética e política. São Paulo: Ed. 34.

Rancière, J. (2010). A associação entre arte e política. Revista Cult, 13, 123-133. Entrevista concedida a Gabriela Longman e Diego Viana.

Rancière, J. (2012). O espectador emancipado. São Paulo: Editora WMF Martins Fontes.

Sansão, A. F. (2012). Intervenções temporárias e marcas permanentes na cidade contemporânea. Arquiteturaerevista, 8(1), 31-48.

Santoro, V. C. (2006). Clínica psicanalítica e ética. Reverso, 28(53), 61-66.

Recebido: Fev. 03, 2016

Aprovado: Set. 29, 2016 